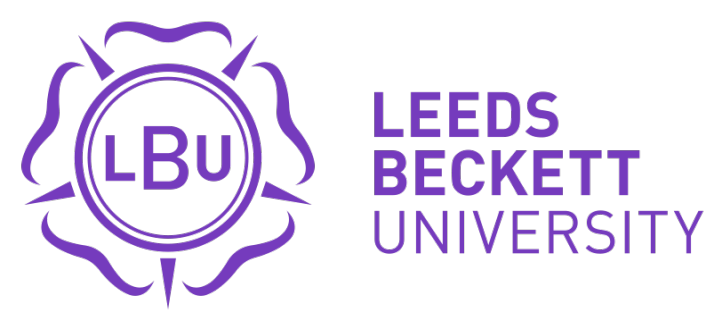

Citation:

Kostopoulos, G and Rizomyliotis, I and Konstantoulaki, K (2015) Determinants of physicians' purchase intention for innovative services: Integrating professional characteristics with technology acceptance model and theory of planned behaviour. International Journal of Innovation Management, 19 (2). ISSN 1363-9196 DOI: https://doi.org/10.1142/S1363919615500243

Link to Leeds Beckett Repository record:

https://eprints.leedsbeckett.ac.uk/id/eprint/1573/

Document Version:

Article (Updated Version)

The aim of the Leeds Beckett Repository is to provide open access to our research, as required by funder policies and permitted by publishers and copyright law.

The Leeds Beckett repository holds a wide range of publications, each of which has been checked for copyright and the relevant embargo period has been applied by the Research Services team.

We operate on a standard take-down policy. If you are the author or publisher of an output and you would like it removed from the repository, please contact us and we will investigate on a case-by-case basis.

Each thesis in the repository has been cleared where necessary by the author for third party copyright. If you would like a thesis to be removed from the repository or believe there is an issue with copyright, please contact us on openaccess@leedsbeckett.ac.uk and we will investigate on a case-by-case basis. 


\title{
Determinants of Physicians' Purchase Intention for Innovative Services. Integrating Professional Characteristics with Technology Acceptance Model and Theory of Planned Behaviour
}

Giannis Kostopoulos ${ }^{a}$, Ioannis Rizomyliotis ${ }^{\text {b }}$, Kleopatra Konstantoulaki c

\begin{abstract}
This paper seeks to explore the factors that influence physicians' purchase intention for supplementary professional services that have been recently introduced to the market. For that reason, a model has been developed and empirically tested using data collected from 100 physicians regarding an innovative e-detailing service. Results show that physicians' purchase intention is significantly influenced by five factors. Three of them derive from the integration of Technology Acceptance Model (TAM) with the Theory of Planned behaviour (TPB), i.e. perceived usefulness, perceived ease of use and professional image. The rest, namely work experience, working status and innovativeness, refer to physicians’ professional characteristics. Work experience and innovativeness were found to have a significant effect on physicians' perceptions of the innovative service, whereas, physicians' current working status was not found to have significant influence on either their perceptions of the innovative service or their purchase intention.
\end{abstract}

Keywords: Innovative Services, TAM model, Professional characteristics

a. Leeds Metropolitan University, City Campus, Leeds, LS13HE

b.Brighton Business School, University of Brighton, Mithras House, Lewes Road Brighton, BN2 4AT

c. Westminster Business School, 35 Marylebone Rd, London NW1 5LS, UK

Corresponding Author: Dr Ioannis Rizomyliotis, email: i.rizomyliotis@brighton.ac.uk, tel.: 0044 (0) 7743500885 


\section{Introduction}

The survival of post-industrial organisations today largely lies on their behaviour towards innovation (Tödtling, Lehner and Kaufmann, 2009). Innovation represents a means by which they can exploit change as an opportunity for a different business or a different service (Drucker, 2007). In line with this aspect, innovation, if carefully implemented, can lead to improved productivity and provide the basis for a competitive advantage (Knani, 2013), while at the same time, according to Tushman and O'Reilly (2006), the success of many contemporary organisations depends on their ability to incorporate innovation into their culture. Similarly, super - diffusion innovations are having today an intense effect on consumer behaviour (Dickson, 2000) and high-leveled investments are made in the use of sophisticated innovative systems in various fields of traditional economy (agriculture, manufacturing, wholesale, retail trade) and in the services sector (professional, healthcare services). The latter category, that of professional services in the healthcare industry, where the dimensions of innovation adoption are yet to be further explored, is the prime focus of this study.

Whilst innovation in professional services has long been considered as a major source of competitive advantage for both the provider and the buyer (e.g. Bharadwaj et al, 1993; Chapman et al, 2003; Kandampully and Duddy, 1999; Vecchiarini and Mussolino, 2013), the prediction of an innovative service adoption rate is still a real hazard for service providers (Sawang and Unsworth, 2011; Jackson, Yi and Park, 2013). For many years, academics have attempted to put light on the factors that determine the potential buyers' behavioural intentions towards innovative services (e.g. Nuq and Aubert, 2013) in their effort to increase their understanding of innovation adoption drivers. Most of the on-going research is based on the Technology Acceptance Model (TAM), a theoretical model which was firstly introduced by Davis (1989) and rests on the investigation of a wide variety of innovation adoption 
predictors in different contexts and for different types of potential users (e.g. Jeyaraj, Rottman and Lacity, 2006; Venkatesh and Davis, 2000; Gefen and Straub, 1997; Kimberly and Evanisko, 1981; Sherer, 2010).

However, TAM - based studies have mostly investigated innovation adoption for general user populations only; in other words, the focus was directed towards professionals from different and diverse occupational settings who utilise various types of technological innovation (e.g. Gefen and Straub, 1997; Venkatesh and Morris, 2000). Enlightening as this may have been, it could also lead to ambiguous or contradictory findings regarding purchase intentions, as different professional characteristics may in turn have a different effect on the technology acceptance process. Only recently have innovation researchers realised the importance of professional characteristics and the need for special attention to industry specific professional groups in order to interpret the innovation adoption process (e.g. Abdolrasulnia et al, 2008; Kamhawi, 2008; Davidson and Chismar, 2007).

This population - specific research stream is partly directed towards the healthcare industry (e.g. Davidson and Chismar, 2007: Sherer, 2010; Alkhateeb, Khanfan and Loudon, 2010). Similarly to professionals in traditionally stable environments, healthcare professionals and organisations seem to continually adopt technological innovations over the last few decades, whilst they increasingly attempt to establish their competitive position based on innovation (Vecchiarini and Mussolino, 2013). The struggle for organisational survival in a rapidly changing environment like the health care industry requires that organisations adopt technological innovations on a regular basis (Wilson, Ramamurthy and Nystrom, 1999). According to Ghodeswar and Vaidyanathan (2007), the healthcare industry is indeed characterised by a rapid and continuous introduction of innovation (Davidson and Chismar, 2007), the adoption of which could readily offset competition. Interestingly though, technology adoption has been relatively slow in the healthcare industry, a fact attributed to 
factors specific to the medical profession and physicians' nature in particular (Seeman and Gibson, 2009).

Physicians indeed differ significantly from general users (Ford, Manachemi and Phillips, 2006). They are highly skilled and highly educated professionals trained to work in a complex and stressful environment like the healthcare industry is (Seeman and Gibson, 2009). At the same time, in most cases they (normally) demonstrate a strong sense of autonomy (Walter and Lopez, 2008; Seeman and Gibson, 2009). What's more, they tend to have increased control over a buying process that relates to their job and are more likely to be involved in different buying activities than users in other settings do, when the purchase item involves specialised considerations (Ghodeswar and Vaidyanathan, 2007). Therefore, whilst the majority of the research body regards them as regular users who only adopt a particular innovation when this is imposed in their working environment, they can't be seen as consumers or employees. On the contrary, the purchases they are involved in are in fact b2b transactions (Park and Kim, 2003), regardless if they act as self-employed professionals or employees in healthcare organisations (Ghodeswar and Vaidyanathan, 2007). On top of that, their particular professional characteristics have been shown to significantly influence their purchase behaviour as well as the outcome of relevant purchase functions (Venkatesh and Davis, 2000; Seeman and Gibson, 2009).

Surprisingly enough, the investigation of physicians' professional characteristics as drivers of their purchase behaviour has been neglected by previous research. Pertinent studies suggest that physicians are potential innovation users (Sherer, 2010; Alkhateeb, Khanfan and Loudon, 2010;) and hence solely investigate the influence of TAM - based predictors on their purchase intention. Existing literature also integrates variables deriving from the Theory of Planned Behaviour (TPB), according to which, purchase intentions and behaviours are shaped by one's attitude toward behaviour, subjective norms, and perceived behavioural control 
(Mitchell et al, 1996; Venkatesh and Davis, 2000; Chau and Hu, 2002b; Yi et al, 2006; Seeman and Gibson, 2009). Still, to the best of our knowledge, there is no study that integrates-physicians' professional characteristics with the aforementioned theories.

To this aim, the present study seeks to make a contribution to the extant literature by synthesising physicians' professional characteristics with variables deriving from the integration of TAM and TPB in order to provide a more comprehensive prediction model of their purchase intention for innovative services. In effect, this study extends the scope of research on physicians' purchase intention to include the direct and indirect influence of physician's professional characteristics, namely innovativeness, work experience and working status.

The results may give practitioners a better understanding of physicians' buyer behaviour, which can then be used to devise their strategies and mechanisms to encourage innovation adoption, especially in the emerging area of online services. Thus, the objectives of this study are as follows:

1. To propose and evaluate the integration of physicians' professional characteristics with TAM and TPB as a solid theoretical basis for the prediction of innovative services adoption.

2. To investigate whether physicians' professional characteristics significantly affect their purchase intention to use innovative services.

The rest of the paper proceeds as follows: Section 2 introduces the underlying theory and theoretical foundations and outlines our hypotheses and research model. In section 3 our methodology and research design are discussed in detail and section 4 presents the data analysis and hypotheses testing results. Next (section 5) we discuss the research findings and managerial implications of the study. Finally, limitations of the study and suggestions for future research are also provided (section 6). 


\section{Literature Review}

\subsection{Technology Acceptance Model and Physicians’ Behavioural Intention}

TAM was developed (Davis, 1989; Davis et al, 1989) to explain people's behavioural intention related to the use or purchase of a technological innovation. The two predictors primary used for that were: Perceived Ease of Use, which is defined as "the degree to which a person believes that using a particular system would be free of effort” (Davis, 1989, pp. 320) and Perceived Usefulness, which refers to "the degree to which a person believes that using a particular system would enhance his or her job performance” (Davis, 1989, pp. 320). The importance of these two variables in explaining the variation in individuals' intention to adopt an innovation has been confirmed by several meta-analysis reports (e.g. Schepers and Wetzels, 2007) and by several empirical studies on either consumers or business users (e.g. Yi et al, 2006). Some of the pertinent studies have used physicians as the sample unit and reported that physicians' intention to use innovative services is indeed predicted by the two factors deriving from TAM (e.g. Mitchel et al, 1996; Yi et al, 2006; Seeman and Gibson, 2009, Chismar and Wiley-Patton, 2003). Hence, in the present study we propose that both perceived ease of use and perceived usefulness have a significant influence on physicians' behavioural intentions and we post that:

$\boldsymbol{H}_{1}$ : Perceived ease of use positively influences physicians' intention to adopt innovative services.

$\mathbf{H}_{2}$ : Perceived usefulness positively influences physicians' intention to adopt innovative services.

\subsection{Theory of Planned Behaviour and Physicians’ Behavioural Intention}


In an attempt to better explain innovation acceptance behaviours many researchers have revised TAM by introducing other variables as predictors of potential users' intention to adopt an innovative product or service (e.g. King and He, 2006; Bagozzi, 2007). In doing so, they have tested variables like resistance to change (Bhattacherjee and Hikmet, 2007), self-efficacy (Kumar and Uzkurt, 2010), specialty (Alkhateeb, Khanfar, Doucette and Loudon, 2009), and several external factors (e.g. word of mouth, Carter and Chitturi, 2009; government support, Nuq and Aubert, 2013),

With more than twenty studies testing TAM in healthcare (e.g. Seeman and Gibson, 2009; Bhattacherjee and Hikmet, 2007) and several health IT papers discussing the model, TAM is portrayed as a fitting theory for the healthcare sector, albeit not developed specifically for the health care context (Holden and Karsh, 2010). Nonetheless, TAM alone is not adequate to predict innovation acceptance behaviour as it may not capture some of the unique contextual features of healthcare professionals (Holden and Karsh, 2010). Physicians' personal characteristics (e.g. demographic attributes; Alkhateeb and Doucette, 2009), attitude towards technology, perceived behavioural control, prior use and subjective norms (e.g. Jackson et al, 1997; Igbaria et al, 1997; Venkatesh and Davis, 2000; Bagozzi, 2007) have all gained researchers' attention in their attempt to extend TAM's predictive power.

The latter variable derives from the TPB and is probably the most controversial parameter, since many studies have reported subjective norm's significant influence on behavioural intentions, whereas others have found the same influence to be insignificant (Chen et al, 1998; Chau and $\mathrm{Hu}, 2002 \mathrm{a}$; Venkatesh and Davis, 2000). In general, subjective norm refers to the influence that the judgment of significant others can have on individual's perception about a behaviour in question (Fishbein and Ajzen, 1975). These social-normative pressures also play a major role in individuals' decisions to adopt innovation (van den Bulte and Lilien, 2001), which, in turn, are reported to be a function of exposure to other actors' knowledge, attitudes, 
or behaviours concerning the innovative product/service (Ford, Menachemi, Peterson and Huerta, 2009).

In the case of physicians' purchase intention towards an innovative service, subjective norm refers to the perceived pressure coming from significant actors' (e.g. patients, colleagues) judgment about their professional image as a result of the innovation adoption. Physicians have historically relied upon their professional peers' opinion with respect to new technology adoption (Audet, Doty, Shamasdin and Schoenbaum, 2005). Contrary to Chau and $\mathrm{Hu}$ (2002a) who suggest that subjective norm has no significant effects on physicians' behavioural intention, there are various theoretical accounts of social pressures and network effects which lead us to believe that significant others' perceptions of physicians' professional image will have a significant influence on their behavioural intentions towards innovative products/services (Moore and Benbasat, 1991; Venkatesh and Davis, 2000; Alkhateeb, Khanfar and Loudon, 2010). Evidently, this emerges from the commonly accepted notion that the adoption of a high-tech innovative service or product acts as an effective signal of enhanced status and an indication of personal innovativeness (Wood and Hoeffler, 2012); this appears to be of paramount importance to physicians (Venkatesh and Davis, 2000; Yi et al, 2006; Nuq and Aubert, 2013).

In order to test if the widely accepted influence of significant others on individuals' behavioural intention applies to physicians' purchase intention, the variable of subjective norm that derives from TPB is embedded in our model. Hence, we investigate whether subjective norms regarding physicians' professional image have a positive influence on their purchase intention for innovative services based on the following hypothesis:

$\boldsymbol{H}_{3}$ : Other people's perceptions on physicians' professional image after adopting an innovative service positively influence their intention to adopt such services.

\subsection{Physicians’ Buyer Behaviour}


As noted earlier, physicians are professionals whose buying behaviour deserves particular attention. Acting more like a buying center rather than a consumer or an industrial buyer (Brown et al 2012), physicians make innovation adoption decisions in a way that differentiates them from other business users and therefore should be treated as a distinct group of professionals with regards to adoption. Results from various studies (Chau and $\mathrm{Hu}$, 2002a; Chau and Hu, 2002b; Hu, Chau and Sheng, 2002; Hu, Chau, Sheng and Tam, 1999; Kohli, Piontek, Ellington, VanOsdol, Shepard and Brazel, 2001) suggest that these differences from other users in terms of technology acceptance originate from physicians' specialised training, autonomous practices, and professional work arrangements (Walter and Lopez, 2008).

Physicians operate in a rather close-knit community and any external influence or intervention in their decision-making is seen as an assault on their freedom and autonomy. (Ford, Menachemi, Peterson and Huerta, 2009). Professional autonomy is defined as professionals' having control over their work's processes and content according to their own judgment in the application of their profession's body of knowledge and expertise (Raelin, 1989). Physicians are, thus, granted to control and regulate their own practices on the basis that they are at the top of the hierarchy in terms of specialised expertise and knowledge in their profession (Walter and Lopez, 2008).

What's more, researchers (Ford, McAlearney, Phillips, Menachemi and Rudolph, 2008) have noted that physicians form a distinct and worth examining group of users as they are a blend of older physicians who are still resisting the adoption of innovation and newer ones who have increased familiarity with new technologies. As a result of this seeming situation, they respond to innovation adoption differently from other users (Mairinger et al, 1998) while at the same time they appear to be more likely to consider factors other than innovation usefulness or ease of use (Paul and McDaniel, 2004) 


\subsection{Professional Characteristics and Physicians’ Behavioural Intentions}

Many authors have picked on physicians' characteristics and practices to investigate their association with technology adoption (Tamblyn et al, 2003). For example, practice size (Hing, Burt, and Woodwell 2007; DesRoches et al. 2008), practice payer mix (Menachemi et al. 2007; Abdolrasulnia et al. 2008), physician age (Menachemi and Brooks, 2006), and physician specialty (DesRoches et al. 2008; Simon et al. 2008), have all been linked to IT systems (e.g. Electronic Health Record) adoption. Still, the extant literature on the antecedents of physicians' purchase intention for innovative services neglects the importance of physicians' professional characteristics. In order to fill this gap in theory and in line with previous studies (e.g. Yi et al, 2006), we suggest that physicians' professional characteristics should be taken into serious consideration, since the variables deriving solely from TAM and TPB cannot fully explain the variations in physicians' purchase intention. The professional characteristics we included in our conceptualization are: Physicians Innovativeness, Work Experience and Working Status.

\subsubsection{Innovativeness}

Innovativeness refers to the evident inclination to be a pioneer and thought leader with regards to technology; meaning that people scoring high in technology innovativeness have stronger intrinsic motivations to accept new technology or even enjoy trying new technology (Agarwal and Karahanna, 2000). These pioneers or early adopters of innovation would be willing to use it even when the potential benefits were still uncertain (Walczuch, Lemmink and Streukens, 2007). According to innovation diffusion theory people react differently to innovative products and services, based on their innovativeness (Agarwal and Karahanna, 2000). In essence, individuals with high innovativeness are, positively disposed to a new technology and its usefulness (Walczuch, Lemmink and Streukens, 2007), which, in turn, makes them more open to adopting innovative products, services (Liang et al, 2003; Lu et al, 
2005) or procedures (Kumar and Uzkurt, 2010).

Innovativeness, is also central to understanding how professionals behave towards innovative services/products (Hurley, Hult, and Knight, 2005); it is a professional characteristic that has a major impact on their work (Jaakkola and Renko, 2007). Physicians, in particular, as noted by Glass and Rosenthal (2004) and Carter and Chitturi (2009) are not always potential innovators. What's more they are a diversified group of professionals in terms of their approach towards technology; some of them are not technologically literate (Mitchell et al, 1996) and express a resistance to change in the work processes in which they are involved (Bhattacherjee and Hikmet, 2007) while others have significant familiarity with new technologies (Ford, McAlearney, Phillips, Menachemi and Rudolph, 2008). Notwithstanding, they all are highly educated and capable in learning new things (Mitchell et al, 1996), so innovativeness is expected to positively influence their perceptions, to the extent that the innovative service fits in their practice or improves their image (Ajami and BagheriTadi, 2013). On top of that, innovativeness is regarded as a determinant of innovation's perceived ease of use and perceived usefulness (Agarwal and Prasad, 1998; 1999).

Finally, as previously stated, physicians are autonomous professionals whose purchase decisions are similar to those of a company's buying center (Brown et al 2012). Like industrial managers, it is through innovativeness that they evaluate a new service and devise solutions to problems and challenges within their profession (Hult, Hurley and Knight, 2004). The professionals that are in general more innovative will be more likely to purchase innovative products and services irrespective of their perceptions of the innovation characteristics (Yi et al, 2005).

On the grounds of the previous discussion, it is reasonable to formulate the following research hypotheses: 
$\boldsymbol{H}_{4 a}$ : Physicians' innovativeness positively influences their perceptions on the usefulness of an innovative service.

$\boldsymbol{H}_{4 b}$ : Physicians' innovativeness positively influences their perceptions on the ease of use of an innovative service.

$\boldsymbol{H}_{4 c}$ : Physicians' innovativeness positively influences their perceptions on their professional image improvement.

H5: Physician's innovativeness positively influences their intention to adopt innovative services.

\subsubsection{Work Experience}

Prior literature has linked experience to the adoption of technological innovations (e.g. Venkatesh, Thong and $\mathrm{Xu}, 2012$ ). In general, physicians tend to be very confident and autonomous within their profession, an attribute that derives from their highly demanding education, their specialised knowledge and skills (Chau and Hu, 2002a). As a result, they tend to be dubious and sometimes reluctant to accept the proliferation of technology or to adopt innovative methods in contrast to their traditional working routines (Menachemi and Brooks 2006, Anderson and Aydin, 1997). This becomes more intense as physicians become more experienced. This resistance to change in their working practice and the tendency to avoid new ways of working can have a negative impact on both their attitude towards an innovative service and their intention to adopt a new technology (Harrison et al, 2002). Research has also shown that younger physicians will adopt technologies more quickly than their established colleagues (e.g. Ford, McAlearney, Phillips, Menachemi and Rudolph, 2008). According to Alkhateeb, Khanfar and Loudon (2010), as physicians' years in practice increase, they become less eager to adopt new technologies. This implies a significant negative influence of work experience on purchase intention for innovative services, which is both direct and 
indirect through its negative impact on physicians' perceptions for innovative services. Hence we post that:

$\boldsymbol{H}_{6 a}:$ Physicians' work experience negatively influences their perceptions on the usefulness of an innovative service.

$\boldsymbol{H}_{6 b}$ : Physicians' work experience negatively influences their perceptions on the ease of use of an innovative service.

$\boldsymbol{H}_{6 c}$ : Physicians' work experience negatively influences their perceptions on their professional image improvement.

$\boldsymbol{H}_{7}$ : Physician's work experience negatively influences their intention to adopt innovative services.

\subsubsection{Working Status}

Despite the fact that physicians are by definition autonomous and self-regulated professionals (Ford, Menachemi, Peterson and Huerta, 2009; Freidson, 1988), their working status can have a significant influence on the way they make innovation adoption decisions. Having their status of employment (clinic/hospital employee vs self-employed physician) as the basis for insight into physicians' behaviour, it is expected that the self-employed ones are far more likely to adopt an innovation for three main reasons. Firstly, self-employed physicians have more autonomy and behavioural control over a purchase and, hence, will have more reasons to find an innovative service immediately useful and easier to use (Venkatesh, 2000; Wu and Chen, 2005). Moreover, self-employed physicians are expected to be more positively inclined towards a potential innovation because of the positive effect the latter may have on their professional image. Self-employed physicians are supposed to be responsible for their own professional image development, and thus perceive the potential innovation adoption as being directly beneficial for their image. On the contrary, the 
establishment of a reputable professional image for those employed in a health care organisation heavily relies upon their employer's image and as a result they are not expected to value a potential innovation as much as self-employed physicians do.

Finally, self-employed physicians are more likely to purchase an innovative service, as they are expected to feel less threatened by the adoption of an innovation. As noted earlier, physicians working as employees in health care organisations often face new technology as a threat for their freedom and autonomy (Ford, Menachemi, Peterson and Huerta, 2009). Contrary to solo practitioners they are more concerned over a possible loss of their autonomy (Borkowski and Allen, 2003) and, thus, they tend to show resistance to the adoption of new services/products within their working practice (Harrison et al, 2002). Self-employed physicians on the other hand have been found to be heavy users of e-technology; more specifically, the adoption rate decreases as the size of the practice increases (Boehm, 2005). Therefore, it becomes clear that a physicians' work status directly influences their intention to adopt an innovative service.

All the above, lead as to formulate the following research hypotheses:

$\boldsymbol{H}_{\mathbf{8 a}}$ : Physicians' working status influences their perceptions on the usefulness of an innovative service.

$\boldsymbol{H}_{8 b}$ : Physicians' working status influences their perceptions on the ease of use of an innovative service.

$\boldsymbol{H}_{8 \mathrm{c}}$ : Physicians' working status influences their perceptions on their professional image improvement.

H9: Physicians' working status influences their intention to adopt innovative services.

All pertinent interrelations described in the research hypotheses of the study are presented in the proposed research model, which is illustrated in Figure 1. 


\section{Insert Figure 1}

\section{Methodology}

\subsection{Sampling and Data Collection}

In order to empirically test the validity of the study's conceptual framework we carried out a primary, quantitative field study in Greece, approaching physicians at their working environment. The specific research design was chosen in order to increase the generalisability of the results to the population, (Parasuraman et al, 2006). From the total population of approximately 72,000 physicians in Greece (OECD Health Data, 2013), we randomly selected and conducted 252 physicians, of whom 100 agreed to participate in our research, deriving a response rate of $39.6 \%$, which we consider very high given the limited available time of our sample unit. The specific sample size was determined accordingly, in order to enable the use of Structural Equation Modeling in the statistical analysis of the data and increase the results validity, as suggested from the pertinent literature (Fan et al, 1999). In the final sample, nine different types of physicians were included (Table 1) in comparison to the population of physicians in Greece no type of physician was overrepresented or underrepresented.

All physicians completed a structured questionnaire in presence of a fellow researcher. The specific data collection method was chosen in order to assure physicians' participation and hence increase the study's response rate (Aaker et al, 2008). This method has also disadvantages, the most important of which is that the responses might be biased due to the possibility of the participants feeling stressed or uncomfortable from the interviewer's presence (Parasuraman et al, 2006). In this case however, the possibility of such bias to occur was very low, since the participants are highly competent professionals and the questions included in the research instrument were not personal, difficult or ambiguous. Hence, we can conclude that the reliability of the participants responses in adequate. 
The questionnaire was focused on a new electronic detailing (e-detailing) service, which is an innovative to the local market online service. In general, e-detailing refers to "the use of digital technology, in the detailing process, therefore many formats are possible including use of technologies, such as the Internet, videoconferencing and interactive voice conferencing (IVR) for enabling the interaction with the physician"' (Bates et al, 2002, p. 257). The innovative e-detailing service used in the questionnaire of the present study refers to an online platform which facilitates a two-way communication process between pharmaceutical companies and physicians. Specifically, through this platform pharmaceutical companies are able to sent messages and promote products to physicians, who in turn are able to provide feedback to their suppliers, make orders and search for new products. The service is accessible through personal computers, tablets and smartphones.

E-detailing was introduced to the international market in the second half of the millennium decade (Alkhateeb et al, 2009). Nevertheless, according to marketing and sales executives in the corresponding industry in Greece, by the time the present research was carried out this service had received little, if any, attention by physicians in Greece and very few pharmaceutical companies were actually using it (Pmjournal, 2012). Therefore, we consider e-detailing as an innovative on-line service for the Greek pharmaceutical market.

\subsection{Operationalisation of Variables}

In order to measure the constructs included in our conceptual framework, where possible, we employed formerly developed and tested scales. To capture perceived usefulness, ease of use and physicians' perceived professional image we used scales developed and empirically validated by Davis (1989), using Likert-type items with anchors 1-7. The possibility of purchasing the proposed online services was addressed through a single item scale asking: "How possible do you think it will be to use the described service in the next 12 months". 
For the measurement of physicians' innovativeness we used a six-item, five-point Likerttype scale adopted from Goldsmith and Hofacker (1991) measuring the tendency to learn about and adopt innovations within a specific domain of interest. Professional experience was measured objectively by the years of the physician's employment, whereas working status describes whether a physician is currently self-employed (they run their own small or medium practice) or employed in a clinic/hospital either public or private (dichotomous variable).

Confirmatory factor analysis (CFA) was employed to all multi-item scales in order to examine their unidimensionality as well as discriminant and convergent validity (Table 2). In all cases, the measures were proven to be unidimensional and valid both in terms of discriminant and convergent validity, as proven by the pertinent fit indices and from the percentage of the latent variables' explained variance (Average Variance Extracted, AVE), which is more than $50 \%$ for all variables (Fornell and Larker, 1981). All measures were also examined for internal consistency as reflected by construct reliability assessed through the calculation of the Cronbach a coefficient. As shown in Table 2 the coefficients' value was substantial $(>0.7)$ for all multi-item scales, which proves that all of them can be considered reliable. Both the measurements' psychometric properties and the model testing, which will be presented in the following chapter, were examined through the use of EQS 6.2.

\section{Insert Table 2}

\section{Data Analysis}

\subsection{Descriptive Statistics}

Of the 100 physicians, 58 were working in a clinic or a hospital whereas 42 were selfemployed (running a small or medium practice). Regarding the demographic profile of our sample, $66 \%$ of the respondents where males and $34 \%$ females. The average age was 41 and 
the average working experience was 12.4 years. The sample's working status proportion and demographic profile is very similar to the one of the general population of physicians (http://apps.ygeiamap.gov.gr, 2013) enhancing thus the representativeness of the sample. The complete participants' demographic characteristics by working status' category are presented in Table 3.

A careful examination of the self-addressed variables' descriptive statistics (Table 4) indicates that on average the study's participants show a low degree of innovativeness (Mean: 4.132.). On the contrary, their evaluations on the new e-detailing service are relatively positive in terms of the service's Perceived Usefulness (Mean: 5.340), Perceived Ease of Use (Mean: 5.726) and the degree to which they believe that their professional image will be improved from its use (Mean: 5.530). Finally, according to their answers they have a relatively high purchase intention for the service (Mean: 5.542).

\subsection{Hypotheses Testing}

To check the validity of our research hypotheses, we constructed a hypothesised model, which captures the study's conceptual framework (Figure 1) and followed a confirmatory approach, checking the fit of the hypothesised model to the collected data, as well as the significance of all causal relationships within it. For this purpose, we used Structural Equation Modelling (SEM), similarly to previous pertinent studies (e.g. King and He, 2006). In this model Purchase Intention was used as a dependent variable and perceived usefulness, perceived ease of use, professional image, innovativeness, work experience and working status as antecedents, while the influence of the professional characteristics on the three technology acceptance variables was also included. As shown in Table 4, most of the correlations between the variables included in the hypothesized model are statistically 
significant but relatively low, which is probably owed to the relatively small sample size of the study.

\section{Insert Table 4}

The results of the Goodness-of fit test show an excellent fit of the hypothesized model to our data. While the significance of chi-square is approximately zero, the value of most commonly used fit indices (Rigdon, 1996; Byrne, 2006) indicate that the fit of the model (Table 5) is very satisfactory $(\mathrm{CFI}=0.99, \mathrm{GFI}=0.99, \mathrm{TLI}=0.98, \mathrm{RMSEA}=0.057)$.

\section{Insert Table 5}

According to the results of the significance tests for the coefficients of the path model (Table 5), purchase intention is positively and significantly influenced by Perceived Usefulness $(\beta=0.189, \mathrm{t}=4.119)$, Perceived Ease of Use $(\beta=0.149, \mathrm{t}=2.725)$ and Professional Image $(\beta=0.387, \mathrm{t}=9.735)$. Hence, hypotheses $\mathrm{H}_{1}, \mathrm{H}_{2}$ and $\mathrm{H}_{3}$ are accepted. Purchase intention is also influenced by two out of three professional characteristics and specifically by Innovativeness $(\beta=0.135, \mathrm{t}=2.484)$ and Work Experience $(\beta=-0.283, \mathrm{t}=$ 3.910), while the impact of Working Status was not found significant $(\beta=-0.025, \mathrm{t}=-$ 0.165). Therefore, hypotheses $\mathrm{H}_{5}$ and $\mathrm{H}_{7}$ are accepted, whereas $\mathrm{H}_{9}$ is rejected.

Regarding the influence of physicians' professional characteristics on the technology acceptance variables, Innovativeness influences positively and significantly Perceived Usefulness $(\beta=0.426, \mathrm{t}=6.591)$, Perceived Ease of Use $(\beta=0.222, \mathrm{t}=3.408)$ and Professional Image $(\beta=0.214, \mathrm{t}=2.440)$. Hence, hypotheses $\mathrm{H}_{4 \mathrm{a}}, \mathrm{H}_{4 \mathrm{~b}}$ and $\mathrm{H}_{4 \mathrm{c}}$ are accepted. Also, Work Experience has a negative and significant impact on Perceived Usefulness $(\beta=-$ 0.283, $\mathrm{t}=-4.940)$ and Perceived Ease of Use $(\beta=-0.160, \mathrm{t}=-3.042)$, while the corresponding impact on Professional Image was not found significant $(\beta=0.107, \mathrm{t}=1.371)$. Based on these results, hypotheses $\mathrm{H}_{6 \mathrm{a}}, \mathrm{H}_{6 \mathrm{~b}}$ are accepted, while $\mathrm{H}_{6 \mathrm{c}}$ is rejected. Finally, 
Working Status was found to significantly influence Perceived Ease of Use $(\beta=0.257, \mathrm{t}=$ 3.776). Specifically, according to the results, self-employed physicians evaluate the innovative service as easier to use than those who work in a health care organization. The impact of Working Status on Perceived Usefulness $(\beta=0.053, \mathrm{t}=0.264)$ and Professional Image $(\beta=0.214, \mathrm{t}=2.440)$ was not found significant. Therefore, hypothesis $\mathrm{H}_{8 \mathrm{~b}}$ is accepted, whereas hypotheses $\mathrm{H}_{8 \mathrm{a}}$ and $\mathrm{H}_{8 \mathrm{c}}$ are rejected.

\section{Discussion and Managerial Implications}

The model presented in this study proposes the integration of physicians' professional characteristics with TAM and TPB as a theoretical basis for the prediction of innovative services adoption. The empirical test of the model leads us to some very interesting results and implications that may be useful to marketing managers or executives.

To begin with, our results confirm that TAM and TPB provide a useful theoretical framework when attempting to understand professionals' behavioural intention and that both can find applications in a professional context as well. In agreement with previous studies (e.g. Chau and $\mathrm{Hu}, 2002 \mathrm{~b}$; Yi et al, 2006), both variables deriving from TAM (Perceived Usefulness, Perceived Ease of Use) have a positive and significant effect on purchase intention. Thus, managers who design or promote innovative services to physicians, should definetely emphasise the perceived ease of use and the perceived usefulness of innovative services. In doing so, they need to emphasise the attributes that better match job relevant physicians' needs and empirically demonstrate how the service can be of assistance as the innovation can be perceived as a threat to their autonomy (Walter and Lopez, 2008). In other words, the perceived usefulness and perceived ease of use of an innovative service do not only refer to its functionality but also question its immediate relevance to physicians' workflow. 
Additionally, other people's perceptions of physicians' professional image (adapted from TPB theory) tend to positively affect their decision to use innovative services in their work. Apart from the fact that innovative services constitute by default an indication of high prestige, physicians tend to incorporate social influences (especially those coming from within physicians' community) into their own perceptions and judge a service on the basis of the potential status they can bring (Venkatesh and Davis, 2000; Wood and Hoeffler, 2012; Nuq and Aubert, 2013). So, managers designing or promoting innovative services need to increase the source credibility of social information and create communication campaigns that raise the prestige associated with the innovation usage.

Most importantly and in line with existing studies our results confirm that other factors beyond social norms, perceived usefulness and perceived ease of use are also significantly important to consider when investigating innovation acceptance among physicians or professionals in general (Chau and $\mathrm{Hu}, 2002 \mathrm{a}$; Chau and $\mathrm{Hu}, 2002 \mathrm{~b}$; Walter and Lopez, 2008). More specifically, our study further supports that physicians (and maybe other members of professional groups as well) should be seen as users that make innovation acceptance decisions differently than other professionals. As a distinct professional group they have characteristics that should be seriously considered when studying their behaviour towards innovation. To the best of our knowledge, our findings are the first in innovation adoption research to document that physicians' behaviour heavily depends (among others) on some of their professional characteristics.

Building on findings from previous research, our results indicate that physicians' innovativeness positively influences their professional image and purchase intention as well as the way they perceive the innovation's usefulness and ease of use. This means that irrespective of their opinion about the innovation's characteristics, physicians with a predisposed tendency towards innovation are more likely to positively evaluate an innovative 
service and eventually purchase it (Yi et al, 2005). In other words, highly innovative physicians are expected to value a new service more for its innovativeness rather than its practicality (Kuo, Liu and Ma, 2013). This innovative cohort of physicians usually consists of younger physicians, a notion that is also in accordance with our results on physicians' working experience. Consistent with prior research (Anderson and Aydin, 1997), our results also reveal that physicians' work experience negatively affects their purchase intention and their perceptions of an innovative service's usefulness and ease of use. As opposed to experienced professionals who tend to show resistance to change, early career physicians will be eager to try the innovative services and spread the word to older and less innovative physicians, who will nonetheless be susceptible to their influence (Kwon, Choi and Kim, 2007). This confirms the view that younger physicians, who tend to be more innovative, are a more attractive target market for marketing managers. Even when they are not in a position to make a purchase decision, their colleagues will seriously take their opinion into account, as physicians have always relied on their peers' perceptions when deciding for an innovation adoption (Audet, Doty, Shamasdin and Schoenbaum, 2005; Alkhateeb, Khanfar and Loudon, 2010).

Finally, physicians' working status was not found to influence either their opinion about the innovative service or their purchase intention. This can be attributed to their autonomous nature and self-regulatory professional profile, which exists irrespective of their working status. It seems that managers' initial concern should be to ensure that physicians' professional autonomy is not threatened, before designing or promoting innovative services to them. They can then direct their efforts towards the implementation of different tactics based on the aforementioned factors that affect physicians' buying behaviour. Organizational decisions on innovation adoption on the other hand, should be made with attention to physicians' priorities about the nature of their work (Chiasson and Davidson, 2004). 
In all, this study strengthens previous research findings regarding the delicate balance to be achieved among the factors that determine the professional buyers' purchase intentions. The role of professional characteristics was highlighted and their significant effect on physicians' behaviour was stressed out for the first time. Executives and researchers need to further clarify and assess the way distinct professional groups deal with innovation adoption in order to get an integrated perspective of the dynamics of innovation within the professional services sector.

\section{Limitations and Suggestions for Further Research}

Although it offers useful conclusions for academics and practitioners, our study is tempered by some limitations. The first limitation is the sample size of this study. Although the sample size of 100 subjects is acceptable and sufficient to meet this study's goals and perform the analyses, it would be more beneficial to have a larger and more diversified sample size (e.g. by surveying physicians in various countries) in order to increase the external validity of the results and make cross-cultural comparisons. Our study was conducted in a single market for a single period, which of course increases internal validity, but future research could benefit from longitudinal studies in various cultural environments and markets. For instance, other autonomous, high skilled professionals, such as University professors or architects, could be used as a sample unit.

Moreover, the conceptual framework of the study could be wider in scope. Further research on physicians' intention to purchase online professional services should also investigate the influence of other sets of professional characteristics, (e.g. such as selfefficacy, prior similar experience) as well as additional factors deriving from technology acceptance theory (e.g. behavioural control). Future studies could also investigate potential 
moderating influences on the relationship between physicians' professional characteristics and their intention to adopt (purchase) an innovative service. Such moderating variables could include their resistance to change, the perceived adoption costs of the innovation etc.

\section{References}

Aaker, D. A., Kumar, V., \& Day, G. S. (2008). Marketing research $6^{\text {th }}$ edition, John Wiley \& Sons: New York

Abdolrasulnia, M., Menachemi, N., Shewchuk, R. M., Ginter, P. M., Duncan, W. J., \& Brooks, R. G. (2008). Market effects on electronic health record adoption by physicians. Health care management review, 33(3), 243-252.

Agarwal R., \& Karahanna E. (2000). Time flies when you're having fun: cognitive absorption and beliefs about information technology usage. MIS Quarterly, 24(4), 665-694.

Agarwal R., \& Prasad J. (1998). A conceptual and operational definition of personal innovativeness in the domain of information technology. Information Systems Research, $9(2), 204-215$.

Agarwal R., \& Prasad J. (1999). Are individual differences germane to the acceptance of new information technologies? Decision Science, 30(2), 361-391.

Ajami, S., \& Bagheri-Tadi, T. (2013). Barriers for Adopting Electronic Health Records (EHRs) by Physicians. Acta Informatica Medica, 21(2), 129-134.

Alkhateeb, F. M., \& Doucette, W. R. (2009). Influences on physicians' adoption of electronic detailing (e-detailing). Informatics for Health and Social Care, 34(1), 39-52. 
Alkhateeb, F. M., Khanfar, N. M., Doucette, W. R., \& Loudon, D. (2009). Characteristics of Physicians Targeted by the Pharmaceutical Industry to Participate in E-detailing. Health Marketing Quarterly, 26(2), 98-116.

Alkhateeb, F.M., Khanfar, N.M. \& Loudon, D. (2010). Physicians' Adoption of Pharmaceutical E-Detailing: Application of Rogers' Innovation-Diffusion Model. Services Marketing Quarterly, 31(1), 116-132

Anderson, J.G. \& Aydin, C.E. (1997). Evaluating the impact of health care information systems, International Journal of Technical Assessment in Health Care 13(2), 380-393.

Audet, A. M. J., Doty, M. M., Shamasdin, J., \& Schoenbaum, S. C. (2005). Measure, learn, and improve: physicians' involvement in quality improvement. Health Affairs, 24(3), 843-853.

Bagozzi, R. P. (2007). The Legacy of the Technology Acceptance Model and a Proposal for a Paradigm Shift. Journal of the Association for Information Systems, 8(4), 3.

Bates, A., Bailey, E., \& Rajyaguru, I. (2002). Navigating the e-detailing maze. International Journal of Medical Marketing, 2, 255-262.

Bharadwaj, S.G., Varadarajan, P.R. \& Fahy, J. (1993). Sustainable competitive advantage in service industries: A conceptual model and research propositions. Journal of Marketing, 57(4), 83-99.

Bhattacherjee, A., \& Hikmet, N. (2007). Physicians' resistance toward healthcare information technology: a theoretical model and empirical test. European Journal of Information Systems, 16(6), 725-737.

Boehm, E. (2005). Doctors say e-detailing's influence increases. The Forrester Wave: eDetailing. 
Borkowski, N. M., \& Allen, W. R. (2003). Does attribution theory explain physicians' non acceptance of clinical practice guidelines?. Hospital Topics, 81(2), 9-21.

Brown, B. P., Zablah, A. R., Bellenger, D. N., \& Donthu, N. (2012). What factors influence buying center brand sensitivity?. Industrial Marketing Management, 41(3), 508-520.

Byrne, B. M. (2006). Structural Equation Modeling with EQS: Basic Concepts, Applications and Programming, 2nd Edition. In Multivariate Applications Series, Riegert, D. (eds). Lawrence Elrbaum Associates: New Jersey

Carte, F. J., \& Chitturi, R. (2009). Segmentation based on physician behavior: implications for sales forecasting and marketing-mix strategy. Journal of Personal Selling \& Sales Management, 29(1), 81-95.

Chapman, R. L., Soosay, C. \& Kandampully, J. (2003). Innovation in logistic services and the new business model: A conceptual framework. International Journal of Physical Distribution \& Logistics Management, 33(7), 630-650.

Chau, P.Y.K. \& Hu, P.J. (2002a). Examining a model of information technology acceptance by individual professionals: an exploratory Study, Journal of Management Information Systems, 18(4), 191-229.

Chau, P.Y.K. \& Hu, P.J.H. (2002b). Investigating healthcare professionals' decisions to accept telemedicine technology: an empirical test of competing theories. Information\& Management 39(4), 297-311.

Chen, H., Houston, A. L., Sewell, R. R., \& Schatz, B. R. (1998). Internet browsing and searching: User evaluations of category map and concept space techniques. Journal of the American Society for Information Sciences, 49(7), 582-603. 
Chiasson, M. W., \& Davidson, E. (2004). Pushing the contextual envelope: developing and diffusing IS theory for health information systems research. Information and Organization, 14(3), 155-188.

Chismar, W. G., \& Wiley-Patton, S. (2003). Does the extended technology acceptance model apply to physicians? In System Sciences, 2003. Proceedings of the 36th Annual Hawaii International Conference (pp. 8). IEEE. Conference Publications

Davidson, E. J., \& Chismar, W. G. (2007). The interaction of institutionally triggered and technology-triggered social structure change: An investigation of computerized physician order entry. MIS Quarterly, 31(4), 739-758.

Davis, F. D. (1989). Perceived usefulness, perceived ease of use, and user acceptance of information technology. MIS Quarterly 13(3), 319-340.

Davis, F.D., Bagozzi, R.P. \& Warshaw, P.R. (1989). User acceptance of computer technology: A comparison of two theoretical models. Management Science, 35(8), 9821003.

DesRoches, C. M., Campbell, E. G., Rao, S. R., Donelan, K., Ferris, T. G., Jha, A., ... \& Blumenthal, D. (2008). Electronic health records in ambulatory care - a national survey of physicians. New England Journal of Medicine, 359(1), 50-60.

Dickson, P. R. (2000). Understanding the trade winds: The global evolution of production, consumption, and the Internet. Journal of Consumer Research, 27(1), 115-122.

Drucker, P. F. (2007). Innovation and entrepreneurship: Practice and principles. Elsevier: Oxford.

Fan, X., Thompson, B., \& Wang, L. (1999). Effects of sample size, estimation methods, and model specification on structural equation modelling fit indexes. Structural Equation Modelling: A Multidisciplinary Journal, 6(1), 56-83. 
Fishbein, M., \& Ajzen, I. (1975). Belief, attitude, intention and behavior: An introduction to theory and research. Reading, MA: Addison-Wesley

Ford, E. W., McAlearney, A. S., Phillips, M. T., Menachemi, N., \& Rudolph, B. (2008). Predicting computerized physician order entry system adoption in US hospitals: Can the federal mandate be met?. International Journal of Medical Informatics, 77(8), 539-545.

Ford, E. W., Menachemi, N., \& Phillips, M. T (2006). Predicting the adoption of electronic health records by physicians: When will health care be paperless? Journal of the American Medical Informatics Association, 13(1). 106112.

Ford, E. W., Menachemi, N., Peterson, L. T., \& Huerta, T. R. (2009). Resistance is futile: but it is slowing the pace of EHR adoption nonetheless. Journal of the American Medical Informatics Association, 16(3), 274-281.

Fornell, C., \& Larcker, D. F. (1981). Evaluating structural equation models with unobservable variables and measurement error. Journal of Marketing Research 18(1), 39-50.

Freidson, E. (1988). Profession of medicine: a study of the sociology of applied knowledge. University of Chicago Press: Chicago.

Gefen, D., \& Straub, D. W. (1997). Gender differences in the perception and use of e-mail: An extension to the technology acceptance model. MIS Quarterly, 21(4), 389-400.

Ghodeswar, B. M., \& Vaidyanathan, J. (2007). Organisational adoption of medical technology in healthcare sector. Journal of Services Research, 7(2), 57-81

Glass, H. E., \& Rosenthal, B. (2004). Demographics, practices, and prescribing characteristics of physicians who are early adopters of new drugs. Pharm Therapeut, 29(11), 699-708.

Goldsmith, R. E., \& Hofacker, C. F. (1991). Measuring consumer innovativeness. Journal of the Academy of Marketing Science, 19(3), 209-221. 
Harrison, S., Dowswell, G., \& Wright, J. (2002). Practice nurses and clinical guidelines in a changing primary care context: an empirical study. Journal of Advanced Nursing, 39(3), 299-307.

Health Ministry of Greece, (2013), Health Map of Greece, http://apps.ygeiamap.gov.gr, retrieved 26/11/2013.

Hing, E., Burt, C. W., \& Woodwell, D. A. (2007). Electronic Medical Record Use by Officebased Physicians and Their Practices, United States, 2006. US Department of Health \& Human Services, Centers for Disease Control and Prevention, National Center for Health Statistics.

Holden, R. J., \& Karsh, B. T. (2010). The technology acceptance model: its past and its future in health care. Journal of Biomedical Informatics, 43(1), 159-172.

Hu, P.J., Chau, P.Y.K., \& O.R. Sheng, (2002.) Adoption of telemedicine technology by health care organizations: an exploratory study. Journal of Organizational Computing and Electronic Commerce, 12(3), 197-221.

Hu, P.J., Chau, P.Y.K., Liu Sheng, O.R. \& Yan Tam, K. (1999). Examining the technology acceptance model using physician acceptance of telemedicine technology. Journal of Management Information Systems, 16 (2), 91-112.

Hult, G. T. M., Hurley, R. F., \& Knight, G. A. (2004). Innovativeness: its antecedents and impact on business performance. Industrial Marketing Management, 33(5), 429-438.

Hurley, R. F., Hult, G. T. M., \& Knight, G. A. (2005). Innovativeness and capacity to innovate in a complexity of firm-level relationships: A response to Woodside (2004). Industrial Marketing Management, 34(3), 281-283. 
Igbaria, M., Zinatelli, N., Cragg, P., \& Cavaye, A.L.M. (1997). Personal computing acceptance factors in small firms: a structural equation model. MIS Quarterly, 21(3), 279-305.

Jaakkola, E., \& Renko, M. (2007). Critical innovation characteristics influencing the acceptability of a new pharmaceutical product format. Journal of Marketing Management, 23(3-4), 327-346.

Jackson, C.M., Chow, S., \& Leitch, R.A. (1997). Toward an understanding of the behavioral intention to use an information system. Decision Sciences, 28(2), 357-389.

Jackson, J. D., Yi, M. Y., \& Park, J. S. (2013). An empirical test of three mediation models for the relationship between personal innovativeness and user acceptance of technology. Information \& Management, 50(4), 154-161.

Jeyaraj, A., Rottman, J. W., \& Lacity, M. C.(2006). A review of the predictors, linkages, and biases in IT innovation adoption research. Journal of Information Technology, 21(1), 123.

Kamhawi, E. M. (2008). System characteristics, perceived benefits, individual differences and use intentions: a survey of decision support tools of ERP systems. Information Resources Management Journal, 21(4), 66-83.

Kandampully, J., \& Duddy, R. (1999). Competitive advantage through anticipation, innovation and relationships. Management Decision, 37(1), $51-56$.

Kimberly, J. R., \& Evanisko, M. J. (1981). Organizational innovation: The influence of individual, organizational, and contextual factors on hospital adoption of technological and administrative innovations. The Academy of Management Journal, 24(4), 689-713.

King, W. R., \& He, J. (2006). A meta-analysis of the technology acceptance model. Information \& Management, 43(6), 740-755. 
Knani, M. (2013). Exploratory Study of the Impacts of New Technology Implementation on Burnout and Presenteeism. International Journal of Business and Management, 8(22), 92-97.

Kohli, R. Piontek, F. Ellington, T. VanOsdol T., Shepard, M. \& Brazel, G. (2001. Managing customer relationships through E-business decision support applications: a case of hospital-physician collaboration, Decision Support Systems, 32 (2), 171-187.

Kumar, R., \& Uzkurt, C. (2010). Investigating the effects of self efficacy on innovativeness and the moderating impact of cultural dimensions. Journal of International Business \& Cultural Studies, 4 (November), 1-15

Kuo, K. M., Liu, C. F., \& Ma, C. C. (2013). An investigation of the effect of nurses' technology readiness on the acceptance of mobile electronic medical record systems. BMC medical informatics and decision making, 13(1), 1-14.

Kwon, O., Choi, K., \& Kim, M. (2007). User acceptance of context-aware services: selfefficacy, user innovativeness and perceived sensitivity on contextual pressure. Behaviour \& Information Technology, 26(6), 483-498.

Liang, H., Xue, Y., \& Byrd, T. A. (2003). PDA usage in healthcare professionals: testing an extended technology acceptance model. International Journal of Mobile Communications, 1(4), 372-389.

Lu, J., Yao, J. E., \& Yu, C. S. (2005). Personal innovativeness, social influences and adoption of wireless Internet services via mobile technology. The Journal of Strategic Information Systems, 14(3), 245-268.

Mairinger, T., Netzer, T., Schoner, W, \&. Gschwendtner, A. (1998). Pathologists' attitudes to implementing telepathology. Journal of Telemedicine and Telecare, 4(1), 41-46. 
Menachemi, N., \& Brooks, R. G. (2006). Reviewing the benefits and costs of electronic health records and associated patient safety technologies. Journal of Medical Systems, 30(3), 159-168.

Menachemi, N., Saunders, C., Chukmaitov, A., Matthews, M. C., \& Brooks, R. G. (2007). Hospital adoption of information technologies and improved patient safety: a study of 98 hospitals in Florida. Journal of Healthcare Management, 52(6), 398-410.

Mitchell, B.R., Mitchell, J.G., \& Disney, A.P. (1996). User adoption issues in renal telemedicine. Journal of Telemedicine and Telecare, 2(2), 81-86.

Moore, G.C., \& Benbasat, I. (1991). Development of an instrument to measure perceptions of adopting an information technology innovation. Information Systems Research, 2(3),192-222.

Nuq, P. A., \& Aubert, B. (2013). Towards a better understanding of the intention to use eHealth services by medical professionals: The case of developing countries. International Journal of Healthcare Management, 6(4), 217-236.

OECD Helth Data, (2013), http://stats.oecd.org/, retrieved 26/11/2013.

Parasuraman, A., Grewal, D., \& Krishnan, R. (2006). Marketing research 2ne Edition. Houghton Mifflin Company: Boston

Park, C. H., \& Kim, Y. G. (2003). Identifying key factors affecting consumer purchase behavior in an online shopping context. International Journal of Retail \& Distribution Management, 31(1), 16-29.

Paul, D.L. \& McDaniel Jr., R.R. (2004.) A field study of the effect of interpersonal trust on virtual collaborative relationship performance, MIS Quarterly 28(2) 183-227

Pharma Market Journal News, (2012) E-detailing in pharmaceutical marketing, interview with Nikos Kontis, posted 15/11/2012, retrieved 24/11/2012. 
Raelin, J. (1989). An anatomy of autonomy: managing professionals, The Academy of Management Executive, 3(3), 216-228.

Rigdon, E. E. (1996). CFI versus RMSEA: A comparison of two fit indexes for structural equation modeling. Structural Equation Modeling, 3(1), 369-379.

Sawang, S., \& Unsworth, K. L. (2011). A model of organizational innovation implementation effectiveness in small to medium firms. International Journal of Innovation Management, 15(5), 989-1011.

Schepers, J., \& Wetzels, M. (2007). A meta-analysis of the technology acceptance model: Investigating subjective norm and moderation effects. Information \& Management, 44(1), 90-103.

Seeman, E., \& Gibson, S. (2009). Predicting Acceptance of Electronic Medical Records: Is the Technology Acceptance Model Enough?.SAM Advanced Management Journal, 74(4), 21.

Sherer, S. A. (2010). Information Systems and Healthcare XXXIII: An Institutional Theory Perspective on Physician Adoption of Electronic Health Records. Communications of the Association for Information Systems, 26, 127-140

Simon, S. R., Kaushal, R., Cleary, P. D., Jenter, C. A., Volk, L. A., Orav, E. J., \& Bates, D. W. (2007). Physicians and electronic health records: a statewide survey. Archives of Internal Medicine, 167(5), 507-512.

Tamblyn, R., Mcleod, P., Hanley, J. A., Girard, N., \& Hurley, J. (2003). Physician and practice characteristics associated with the early utilization of new prescription drugs. Medical care, 41(8), 895-908.

Tödtling, F., Lehner, P., \& Kaufmann, A. (2009). Do different types of innovation rely on specific kinds of knowledge interactions?. Technovation, 29(1), 59-71. 
Tushman, M. L., \& O'Reilly III, C. A. (2006). Ambidextrous organizations: Managing evolutionary and revolutionary change. In Mayle D. (ed), Managing Innovation and Change ( ${ }^{\text {rd }}$ edition), Sage Publications: California, 170-184.

Van den Bulte, C., \& Lilien, G. L. (2001). Medical innovation revisited: Social contagion versus marketing effort. American Journal of Sociology, 106(5), 1409-1435.

Vecchiarini, M., \& Mussolino, D. (2013). Determinants of entrepreneurial orientation in family-owned healthcare organizations. International Journal of Healthcare Management, 6(4), 237-251.

Venkatesh, V. (2000). Determinants of perceived ease of use: Integrating control, intrinsic motivation, and emotion into the technology acceptance model. Information Systems Research, 11(4), 342-365.

Venkatesh, V., \& Davis, F.D. (2000). A theoretical extension of the technology acceptance model: four longitudinal field studies. Management Science, 46(2), 186-204.

Venkatesh, V., \& Morris, M. G. (2000). Why don't men ever stop to ask for directions? Gender, social influence, and their role in technology acceptance and usage behavior. MIS Quarterly, 24(1), 115-139.

Venkatesh, V., Thong, J., \& Xu, X. (2012). Consumer acceptance and use of information technology: extending the unified theory of acceptance and use of technology. MIS Quarterly, 36(1), 157-178.

Walczuch R, Lemmink J, \& Streukens S. (2007). The effect of service employees' technology readiness on technology acceptance. Inform Management, 44(2), 206-215.

Walter, Z., \& Lopez, M. S. (2008). Physician acceptance of information technologies: Role of perceived threat to professional autonomy. Decision Support Systems, 46(1), $206-215$. 
Wilson, A. L., Ramamurthy, K., \& Nystrom, P. C. (1999). A multi-attribute measure for innovation adoption: the context of imaging technology. Engineering Management, $46(3), 311-321$

Wu, I. L., \& Chen, J. L. (2005). An extension of trust and TAM model with TPB in the initial adoption of on-line tax: an empirical study. International Journal of Human-Computer Studies, 62(6), 784-808.

Yi, M. Y., Jackson, J. D., Park, J. S., \& Probst, J. C. (2006). Understanding information technology acceptance by individual professionals: Toward an integrative view. Information \& Management, 43(3), 350-363. 
Table 1: Types of Physicians Included in the Sample

\begin{tabular}{lc}
\hline Physician Type & Frequency \\
\hline Ophthalmologist & 7 \\
Gynecologist & 14 \\
Otolaryngologist & 7 \\
Pediatrician & 19 \\
Surgeon & 6 \\
Cardiologist & 10 \\
Dermatologist & 9 \\
Gastroenterologist & 5 \\
Pathologist & 23 \\
Total & $\mathbf{1 0 0}$ \\
\hline
\end{tabular}


Table 2: Confirmatory Factor Analysis, Reliability and Validity

\begin{tabular}{llllll}
\hline Constructs & CFI & TLI & RMSEA & AVE & Crobach a \\
\hline Perceived Usefulness & 0.931 & 0.922 & 0.088 & 0.64 & 0.78 \\
Perceived Ease of Use & 0.946 & 0.933 & 0.070 & 0.59 & 0.85 \\
Perceived Professional Image & 0.912 & 0.905 & 0.080 & 0.63 & 0.88 \\
Innovativeness & 0.930 & 0.919 & 0.076 & 0.54 & 0.92 \\
\hline
\end{tabular}


Table 3: Descriptive Statistics for the two Working Status Categories

\begin{tabular}{lccl}
\hline Working Status & Age & Work Experience & Gender \\
\hline Self-employed & 40.74 & 12.01 & $\begin{array}{l}\text { Male: } 58.1 \% \\
\end{array}$ \\
& & & Female: $41.9 \%$ \\
Employed in a health organizations & 40.82 & 12.58 & $\begin{array}{l}\text { Male: } 69.6 \% \\
\text { Female: } 30.4 \%\end{array}$ \\
\hline
\end{tabular}


Table 4: Pearson's Correlation Coefficients and Descriptive Statistics

\begin{tabular}{|c|c|c|c|c|c|c|c|c|}
\hline & US & ES & IM & IN & WE & PI & Mean & St.Dev \\
\hline US & & 0.389 & 0.286 & 0.526 & -0.577 & 0.205 & 5.340 & 1.142 \\
\hline ES & 0.389 & & 0.203 & 0.215 & -0.309 & 0.198 & 5.726 & 1.291 \\
\hline IM & 0.286 & 0.203 & & 0.211 & -0.247 & 0.561 & 5.530 & 1.089 \\
\hline IN & 0.526 & 0.215 & 0.211 & & -0.510 & 0.305 & 4.132 & 1.003 \\
\hline WE & -0.577 & -0.309 & -0.247 & -0.510 & & -0.201 & 12.409 & 3.973 \\
\hline PI & 0.205 & 0.198 & 0.561 & 0.305 & -0.201 & & 5.542 & 0.928 \\
\hline
\end{tabular}

US "Perceived Usefulness"; ES "Perceived Ease of Use"; IM "Professional Image"; IN "Innovativeness"; WE "Work Experience"; PI "Purchase Intention" 
Table 5: Fit Indices and Path Coefficients

\begin{tabular}{l|c|c|c}
\hline \hline CFI $=\mathbf{0 . 9 9}, \mathbf{G F I}=\mathbf{0 . 9 9}$, TLI $=\mathbf{0 . 9 8 ,}, \mathbf{R M S E A}=\mathbf{0 . 0 5 7}$ & & \\
\hline PATH MODEL & $\begin{array}{c}\text { STANDARDIZED } \\
\text { BETA }\end{array}$ & $\mathbf{T}$ & SIG. \\
\hline INNOVATIVENESS $\rightarrow$ PERCEIVED USEFULNESS & 0.426 & 6.591 & $<0.05$ \\
\hline WORK EXPERIENCE $\rightarrow$ PERCEIVED USEFULNESS & -0.283 & -4.940 & $<0.05$ \\
\hline WORKING STATUS $\rightarrow$ PERCEIVED USEFULNESS & 0.053 & 0.264 & $>0.05$ \\
\hline INNOVATIVENESS $\rightarrow$ PERCEIVED EASE OF USE & 0.222 & 3.408 & $<0.05$ \\
\hline WORK EXPERIENCE $\rightarrow$ PERCEIVED EASE OF USE & -0.160 & -3.042 & $<0.05$ \\
\hline WORKING STATUS $\rightarrow$ PERCEIVED EASE OF USE & 0.257 & 3.776 & $<0.05$ \\
\hline INNOVATIVENESS $\rightarrow$ PERCEIVED PROFESSIONAL IMAGE & 0.214 & 2.440 & $<0.05$ \\
\hline WORK EXPERIENCE $\rightarrow$ PERCEIVED PROFESSIONAL IMAGE & 0.107 & 1.371 & $>0.05$ \\
\hline WORKING STATUS $\rightarrow$ PERCEIVED PROFESSIONAL IMAGE & 0.283 & 1.039 & $>0.05$ \\
\hline INNOVATIVENESS $\rightarrow$ PURCHASE INTENTION & 0.135 & 2.484 & $<0.05$ \\
\hline WORK EXPERIENCE $\rightarrow$ PURCHASE INTENTION & -0.283 & -3.910 & $<0.05$ \\
\hline WORKING STATUS $\rightarrow$ PURCHASE INTENTION & -0.025 & -0.165 & $>0.05$ \\
\hline PERCEIVED USEFULNESS $\rightarrow$ PURCHASE INTENTION & 0.189 & 4.119 & $<0.05$ \\
\hline PERCEIVED EASE OF USE $\rightarrow$ PURCHASE INTENTION & 0.149 & 2.725 & $<0.05$ \\
\hline PERCEIVED PROFESSIONAL IMAGE $\rightarrow$ PURCHASE INTENTION & 0.387 & 9.735 & $<0.05$ \\
\hline \hline
\end{tabular}




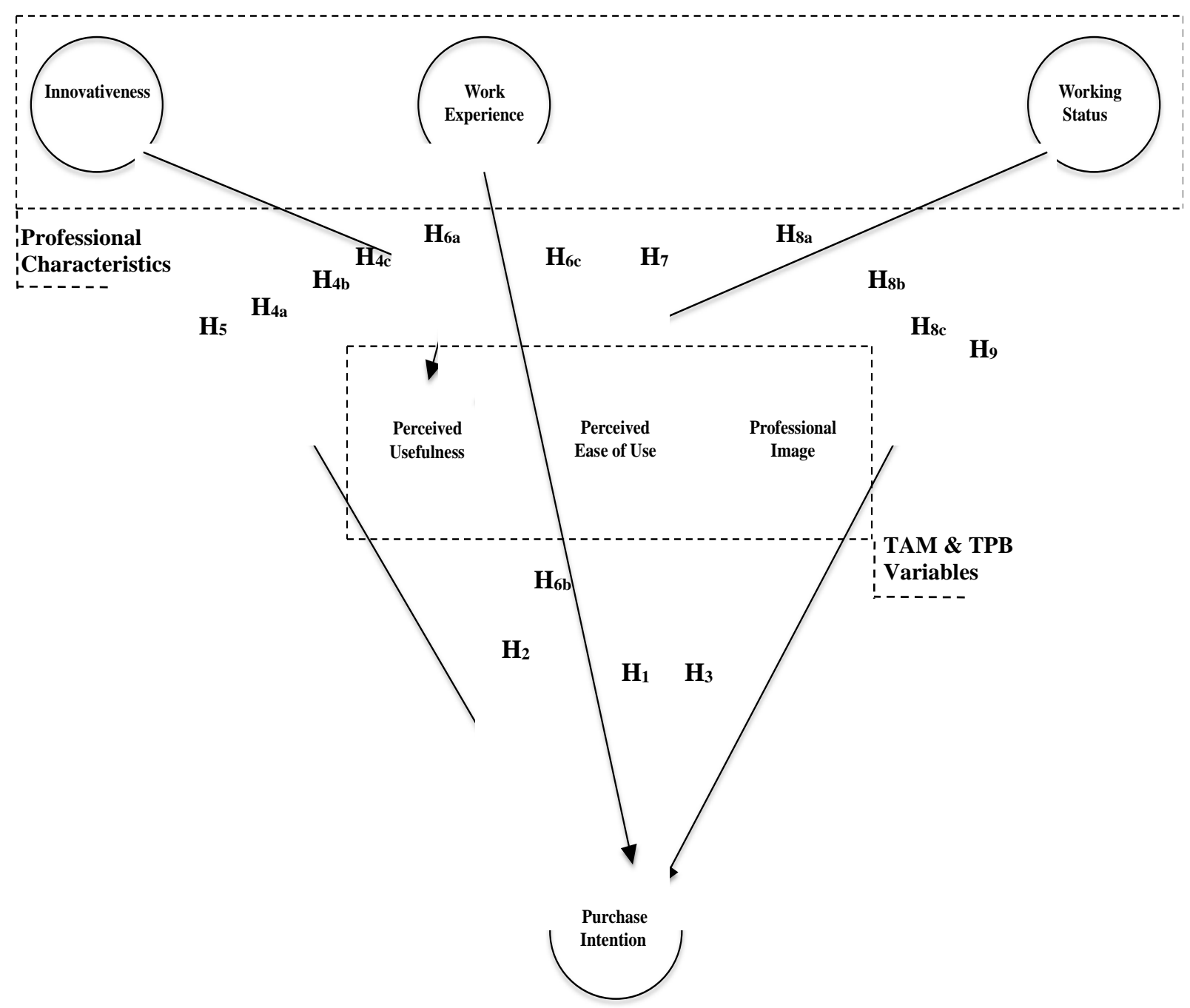

Figure 1: Research Model 